Elsevier Editorial System(tm) for Surface and Coatings Technology

Manuscript Draft

Manuscript Number: SURFCOAT-D-14-00571R2

Title: High Temperature Scratch Testing of Hard PVD Coatings Deposited on Surface Treated Tool Steel

Article Type: Full Length Article

Keywords: High Temperature, Nitriding, PVD Coating, Scratch Test

Corresponding Author: Mr. Jaume Pujante,

Corresponding Author's Institution: Fundació CTM Centre Tecnològic

First Author: Jaume Pujante

Order of Authors: Jaume Pujante; Montserrat Vilaseca, Dr; Daniel Casellas, Dr; Maria Dolors Riera, Dr

Abstract: Scratch testing is one of the most usual characterisation techniques for systems with thin hard coatings. Scratch tests are performed at run at room temperature, due to the risk of degradation of the indenter diamond tip at high temperature and added test complexity. However, results obtained at room temperature may differ from final system performance in high temperature applications, due to factors such as substrate thermal softening.

In this work, a simple and a robust test for the mechanical characterization of hard PVD coatings at high temperature and open atmosphere has been developed, based on a modification of the scratch test where the diamond tip is replaced by a WC indenter. The test has been used to evaluate the effect of temperature up to $500^{\circ} \mathrm{C}$ on commercial PVD AlCrN coating deposited on tool steel subject to different surface treatments. Results show a decrease in the failure load Lc2 with increasing temperature, and a very noticeable effect of substrate nitriding. 


\section{Highlights}

(i) A modified scratch test for high temperature applications has been developed

(ii) Performance of $\mathrm{AlCrN}$-coated 1.2344 has been studied up to $500^{\circ} \mathrm{C}$

(iii) Effect of substrate nitriding on system performance up to $500^{\circ} \mathrm{C}$ has been explored

(iv) Results show the relationship between performance and substrate load bearing capacity 


\title{
High Temperature Scratch Testing OF HaRd PVD CoAtings Deposited on Surface Treated ToOl SteEl
}

\author{
Jaume Pujante $^{1 *}$, Montserrat Vilaseca $^{1}$, Daniel Casellas ${ }^{1}$, Maria Dolors Riera ${ }^{1,2}$ \\ ${ }^{1}$ Fundació CTM Centre Tecnològic, Plaça de la Ciència 2, 08243 Manresa. \\ ${ }^{2}$ Department of Materials Science and Metallurgical Engineering, Universitat Politècnica de \\ Catalunya, Avda. Bases de Manresa 61, 08242 Manresa \\ *Corresponding author: Jaume Pujante (jaume.pujante@ctm.com.es).
}

\begin{abstract}
Scratch testing is one of the most usual characterisation techniques for systems with thin hard coatings. Scratch tests are performed at run at room temperature, due to the risk of degradation of the indenter diamond tip at high temperature and added test complexity. However, results obtained at room temperature may differ from final system performance in high temperature applications, due to factors such as substrate thermal softening.

In this work, a simple and a robust test for the mechanical characterization of hard PVD coatings at high temperature and open atmosphere has been developed, based on a modification of the scratch test where the diamond tip is replaced by a WC indenter. The test has been used to evaluate the effect of temperature up to $500{ }^{\circ} \mathrm{C}$ on commercial PVD AlCrN coating deposited on tool steel subject to different surface treatments. Results show a decrease in the failure load Lc2 with increasing temperature, and a very noticeable effect of substrate nitriding.
\end{abstract}

Keywords: High Temperature; Nitriding; PVD Coating; Scratch Test. 


\section{INTRODUCTION}

Thin ceramic coatings, and hard PVD coatings in particular, show a series of characteristics, such as very high hardness, chemical stability and oxidation resistance, which make them attractive for many high temperature applications, including tooling for hot metal forming, engine components or wear resistant parts.

One of the most common characterization methods for systems including hard coatings is scratch testing [1]. It consists in drawing a hard stylus along the material surface under an increasing normal load, until coating failure. The load at which failure occurs; known as critical load (Lc), is used as a measure of the resistance or durability of the substrate-coating system. Due to its hardness, availability and controlled geometry, scratch testing is most often performed using a diamond tipped hardness indenter, usually with Rockwell $\mathrm{C}$ geometry (sphere-tipped cone) $[1,2]$. Tests are performed at room temperature, to increase simplicity of the testing apparatus and to avoid oxidation or other damages on the expensive indenters.

However, it is known that the performance of coated systems is affected by temperature. For instance, Allsopp and Hutchings [3] performed a series of scratch tests at room temperature and at $350^{\circ} \mathrm{C}$ using a diamond-tipped Rockwell $\mathrm{C}$ indenter. In this study, TiN coatings did not seem to be significantly affected by temperature, while TiCN and AlTiN coatings showed increases in their failure load (from approximately $50 \mathrm{~N}$ at room temperature to more than 100 N). Material rankings were altered when testing at different temperatures, showing that results obtained at room temperature may be misleading for high temperature applications. Similar results were obtained by Fox-Rabinovitch et al [4], who studied the micro-mechanical 
properties at room temperature and $500{ }^{\circ} \mathrm{C}$ of two PVD hard coatings, TiAlN and AlCrN. Several studies were run, including micro-scratch tests, and it was observed that coatings were affected differently by temperature. In terms of scratch resistance, the coating failure load Lc2 decreased for TiAlN-coated samples, but increased slightly for AlCrN. Authors related this behaviour to variations in microhardness and elastic modulus. In another work, Fox-Rabinovich et al [5] analysed the effect of high temperatures on the mechanical properties of PVD-deposited AlTiN. It was observed that samples annealed after deposition retained their mechanical properties at high temperature, while non-annealed samples showed decreased performance. Results were positively correlated with performance in milling tools. In both references [4] and [5] used cemented carbide substrates, thus limiting the influence of substrate thermal softening on coating performance.

Another factor believed to have a significant influence in the performance of a coated system is load bearing capacity provided by the substrate. For instance, combined nitriding and coating deposition, as in Duplex processes, is a growing trend in hot work tool steels, which usually attain overall lower hardness than cold work tool steels and which benefit enormously from the additional load bearing capacity provided by a nitrided substrate. He et al [6] researched the influence of substrate subsurface hardness on the measured coating failure loads, studying nitrided and non nitrided hot work tool steel DIN 1.2367 coated with TiBN and TiCN. Results show that nitriding significantly improves the failure load of the coated system. Analogous results have been obtained by other authors, such as Batista et al [7, 8], working with TiAlN, TiN and CrN on DIN 1.2379 tool steel. However, all these cases include only studies performed at room temperature, and do not explore the persistence of load bearing capacity at elevated temperatures. 
In this work, a simple and robust high temperature scratch test methodology is developed in which the diamond-tipped indenter is replaced by a hard metal blade. These blades can be used at temperatures in excess of $600{ }^{\circ} \mathrm{C}$ and can be easily and inexpensively replaced if deteriorated by wear, oxidation or adhered material. The test is used to study the effect of temperature on an industrial AlCrN coating deposited on hot work tool steel DIN 1.2344, and the influence of the load bearing capacity provided by substrate nitriding. Tests have been performed from room temperature to up to $500^{\circ} \mathrm{C}$ and in open atmosphere, a range of conditions similar to common applications of the studied coating-substrate system such as High Pressure Die Casting and warm/hot forging dies.

\section{METHODOLOGY}

\subsection{Materials}

Disk samples $40 \mathrm{~mm}$ in diameter and $5 \mathrm{~mm}$ thick were machined from DIN 1.2344 tool steel , a standard tool steel used for various hot work tooling applications, heat treated to $52 \pm 1$ HRC. All samples were ground and polished to an arithmetic average roughness Ra under 0.1 $\mu \mathrm{m}$.

Samples B and C were subject to nitriding processes. B-samples were subject to a short plasma nitriding process $\left(4.5 \mathrm{~h}\right.$ at $560^{\circ} \mathrm{C}$ in a $\mathrm{NH}_{3}+\mathrm{CO}_{2}$ atmosphere), resulting in reduced diffusion depth (table 1). C-samples were subject to a longer plasma nitriding, resulting in a thick composite layer and diffusion depth. Afterwards, B and C samples were re-polished to Ra under $0.1 \mu \mathrm{m}$. The reason for this was twofold: on the one hand, surface roughness 
generated in the nitriding process was eliminated, ensuring that all samples had an equivalent surface finish. On the other hand, repolishing allowed eliminating the very thin white layer on B samples, thus obtaining three entirely different substrates. After surface treatment, samples $\mathrm{A}, \mathrm{B}$ and $\mathrm{C}$ were coated with a commercial AlCrN PVD coating. After preparation, crosssectional cuts from each sample were metallographically prepared and studied by means of optical microscopy, in order to obtain full characterization of the studied systems. Figure 1 shows cross-sections from samples B and C; results are summarised in table 1 .

\subsection{Test equipment and procedure}

Modified scratch tests were performed using a Bruker CETR UMT-2 multifunction tribometer, equipped with a high temperature test chamber. The commonly used Rockwell C indenter was in this case replaced by disposable carbide micro-scratch blades, supplied by CETR. These prismatic blades had a rounded corner with nominal $400 \mu \mathrm{m}$ radius and a $6^{\circ}$ angle between the front ant lateral faces. Hardness of the blades was $2070 \pm 25 \mathrm{HV}$. They were mounted on a special holder, with the flat face facing forward forming a $5^{\circ}$ angle with the vertical line, thus ensuring that contact was localised on the tip of the blade corner (figure 2). Each blade tip was used for one test condition, and discarded afterwards to avoid possible inaccuracies due to blade tip wear or oxidation.

Test procedure was analogous to conventional scratch test. Blade tips were loaded against the sample surface at an initial load of $1 \mathrm{~N}$. The indenter was then slid on the surface under linearly increasing load until coating failure. In all cases, sliding velocity of $10 \mathrm{~mm} / \mathrm{s}$ was used. Load rate was initially set at $10 \mathrm{~N} / \mathrm{mm}$, but was reduced to $5 \mathrm{~N} / \mathrm{mm}$ for samples with coating failure load under $10 \mathrm{~N}$, in order to increase test resolution. Tests were performed at 
room temperature, $300{ }^{\circ} \mathrm{C}$ and $500{ }^{\circ} \mathrm{C}$ for all samples. Three single scratches were performed for each test condition in order to ensure result repeatability. Main test parameters are summarised in table 2.

Coefficient of Friction (COF) and Acoustic Emission signal (AE) were registered online during testing, using sensors integrated in the testing apparatus. Measurement of acoustic emission was not possible for $500^{\circ} \mathrm{C}$ tests, as the high temperature would interfere with $\mathrm{AE}$ sensors.

Failure load was identified as peaks in the COF and AE signals. Additionally, scratch tracks were analysed by means of optical microscopy and by optical profilometry, using a SensoFar Pl 2300 confocal microscope. Failure load Lc2 was identified as the point at which delamination occurred (Lc2).

\section{RESULTS AND DISCUSSION}

\subsection{Room temperature characterization}

\subsubsection{Instrumented indentation}

Mechanical characterization of the coated systems was performed by means of instrumented indentation with a Berkovich tip at loads up to $30 \mathrm{~N}$ (figure 3), using a Microindentation Tester MHT (CSM).

Results obtained showed both lower hardness and elastic modulus for sample A compared to nitrided samples B and C. However, samples B and C showed almost identical properties. Sample $\mathrm{C}$ showed a sudden drop in its properties at the indentation depth of $8 \mu \mathrm{m}$ : this was 
related to the fracture of the brittle white layer. Therefore, results corresponding to sample $\mathrm{C}$ need to be analysed taking into account this brittle behaviour.

\subsubsection{Room temperature scratch characterization}

Prior to high temperature scratch testing, samples were characterised by means of conventional, room temperature scratch test performed with a Rockwell C indenter with a 200 $\mu \mathrm{m}$ nominal radius semi-spherical tip. Samples were then subject to the modified scratch test, also at room temperature. Results obtained in these two tests are shown in table 3.

It must be noticed that failure loads obtained with the modified scratch test are much lower that obtained with Rockwell C indenter. This difference is due to the different morphology of the tip: compared to the spherical contact generated using a Rockwell $\mathrm{C}$ indenter, the modified test generates an entirely different stress field. This is consistent with the existing literature; the effect of indenter radius on critical load has been studied experimentally and analytically by various authors, such as Randall et al [9] or Ichimura and Ishii [10]. These studies conclude that sharper indenters result in significantly reduced failure load; however, rankings obtained using each individual indenter geometry are maintained.

In the case of scratches performed with Rockwell $\mathrm{C}$ indenters, all samples showed delamination load Lc2 well over $30 \mathrm{~N}$ for Rockwell $\mathrm{C}$ scratch tests, indicating good adhesion. Both nitrided samples showed resistance over $100 \mathrm{~N}$, maximum for the employed test equipment. This is consistent with results available in the literature, concerning the influence 
of substrate nitriding on coating resistance: works such as He et al [6] and Batista et al [7] report scratch resistance doubling by applying a substrate nitriding treatment prior to coating deposition.

Results obtained with the modified test showed good internal consistency. A clear increase in failure load could be observed for the nitrided sample B $(13.2 \mathrm{~N})$ compared to the nonnitrided sample A $(8.8 \mathrm{~N})$. Moreover, sample $\mathrm{C}$, with a thick composite nitride layer underneath the PVD coating, showed further increase in its performance $(25.3 \mathrm{~N})$. This is, again, in agreement with the results obtained by other authors $[6,7]$. It must however be taken into account that Ichimura and Ishii [10] also note that the effect of indenter geometry is more noticeable with increasing substrate hardness; therefore, the modified test may be more sensitive to substrate hardness variations compared to a Rockwell C hardness indenter.

Comparison of scratch results with the previously shown characterization by means of instrumented indentation is not straightforward. The performance increase observed in scratch results was not detected in $\mathrm{E}$ and $\mathrm{H}$ curves for the studied samples. This can be related to the different loads applied: indentation tests apply normal load over a localised area, while scratch tests create a complex stress field including a friction-generated component and moving over the sample surface.

\subsection{Effect of temperature on AlCrN-coated 1.2344}

Figure 4 shows the obtained Coefficient of Friction and Acoustic Emission measurements (figure 4 a) compared to the scratch track inspected through Optical Microscopy (figure 4 b), corresponding to a test performed at room temperature on sample A. Considering that load is 
increased linearly with displacement in the $\mathrm{x}$ direction, the $\mathrm{X}$ axis of the graph provided can be correlated to displacement along the scratch track. It can be observed that increases in COF and AE signals match to damages observed in the scratch track. In particular, total failure load Lc2 corresponds to both an increase in $\mathrm{COF}$ and $\mathrm{AE}$ and observable delamination on the Optical Microscopy image; the three criteria yield similar results.

This study was performed at room temperature, $300^{\circ} \mathrm{C}$ and $500^{\circ} \mathrm{C}$; three scratches were done in each condition. Results are summarised in Figure 5. Different symbols have been used to plot results obtained through $\mathrm{OM}, \mathrm{COF}$ and $\mathrm{AE}$ measurements; it can be seen that the three criteria offer very similar results in the whole temperature range. An exception must be noted for acoustic emission, which could not be applied in test at $500^{\circ} \mathrm{C}$ due to technical limitations explained before.

A clear tendency of reduction in failure load with increasing temperature could be observed. This decrease was particularly noticeable from room temperature to $300^{\circ} \mathrm{C}$, and more moderate from $300^{\circ} \mathrm{C}$ to $500^{\circ} \mathrm{C}$. This differs from the results obtained by Fox-Rabinovitch et al [4], where it was observed that failure load increased for AlCrN coatings in micro-scratch tests performed at $500{ }^{\circ} \mathrm{C}$, compared to room temperature results. However, studies in reference [4] were performed on coatings deposited on cemented carbide, thus greatly reducing the influence of substrate thermal softening, and test parameters were chosen to concentrate stresses within the coating. In contrast, the methodology used in the present work evaluates the whole coated system, and appears to be noticeably affected by substrate properties. Moreover, the chosen substrate material (tool steel) is more affected by thermal softening than cemented carbide. 
In order to identify this possible contribution of substrate thermal softening to decreased performance, scratch tracks were analysed by means of confocal microscopy. Figure 6 shows failure points corresponding to scratch tracks generated at room temperature (figure 6 a) and $500^{\circ} \mathrm{C}$ (figure $6 \mathrm{~b}$ ). It can be seen that failure at room temperature was sudden, with the indenter breaking through the coating and sinking into the substrate as soon as the critical load Lc2 was reached. On the other hand, the $500^{\circ} \mathrm{C}$ track showed severe plastic deformation of the coated system even before delamination. Failure at $300^{\circ} \mathrm{C}$ (not shown) was similar to $500^{\circ} \mathrm{C}$, showing plastic deformation before failure, but in a lesser extent.

\subsection{Effect of surface treatment on performance at high temperature}

\subsubsection{Effect of temperature on failure load Lc2 for surface treated systems}

Evolution of failure load Lc2 was studied for the three coated systems. Results are summarized in figure 7; each point has been calculated using all values (OM, COF and AE) obtained per coating and temperature level. As discussed in section 3.1, samples with substrate nitriding show higher failure load than non-nitrided samples. Moreover, sample C shows better performance than sample B. This performance improvement is noticeable in the whole temperature range, and could be traced to the improved load bearing capacity provided by a harder substrate, either through nitriding (sample B) or presence of a nitrided layer and a hard composite layer under the coating (sample C).

It must be noticed that relative improvement in failure load decreased with increasing temperature. Sample $\mathrm{C}$ almost tripled failure load of sample $\mathrm{A}$ at room temperature $(8.8 \mathrm{~N}$ for 
sample A, $25.3 \mathrm{~N}$ for sample $\mathrm{C}$ ) and at $300{ }^{\circ} \mathrm{C}$ ( $5 \mathrm{~N}$ for sample $\mathrm{A}, 16 \mathrm{~N}$ for sample $\mathrm{C}$ ), but performance became more similar at $500{ }^{\circ} \mathrm{C}$ ( $4 \mathrm{~N}$ for sample $\mathrm{A}, 6 \mathrm{~N}$ for sample $\mathrm{C}$ ). In all cases, Sample B showed failure loads between Sample A and Sample C.

Scratch tracks were analysed at the moment of failure using confocal microscopy, as shown in section 3.2 for tests on sample A. All three samples showed similar failure mode at room temperature: the coating was cut through suddenly, and indenter sank into the substrate as soon as the coating failed (figure $6 \mathrm{a}$ and figure $8 \mathrm{a}$ and $\mathrm{b}$ ). The same failure mechanism was observed for sample $\mathrm{C}$ at $300^{\circ} \mathrm{C}$ (not shown). Sample B at $300^{\circ} \mathrm{C}$ and Sample C at $500^{\circ} \mathrm{C}$ (figure $8 \mathrm{~b}$ and d) also showed sudden coating failure. In these cases, however, some degree of plastic deformation can be observed on the scratch tracks before failure. Finally, sample B at $500^{\circ} \mathrm{C}$ (not shown) showed similar failure mode as Sample A at $300^{\circ} \mathrm{C}$ and $500^{\circ} \mathrm{C}$, with the coating being delaminated out of a severely deformed wear track.

The effect of load support was further studied by examining the cross-section of the scratch track at the point corresponding to a load of $5 \mathrm{~N}$. This was done for samples A and $\mathrm{C}$, showing the most different behaviours. Results are displayed in figure 9 a (sample A) and figure $9 \mathrm{~b}$ (sample C). Sample A showed little track deformation at room temperature at a load of $5 \mathrm{~N}$, but substrate was considerably deformed at $300^{\circ} \mathrm{C}$ and $500^{\circ} \mathrm{C}$. In the case of sample $\mathrm{C}$, almost no deformation was measured at temperatures up to $300^{\circ} \mathrm{C} ; 500^{\circ} \mathrm{C}$ tracks show considerable deformation. It must be noticed that, even though maximum track depth was higher than the coating thickness $(3 \mu \mathrm{m})$ for sample $\mathrm{A}$ at $300^{\circ} \mathrm{C}$ and sample $\mathrm{C}$ at $500^{\circ} \mathrm{C}$, the system had not failed at $5 \mathrm{~N}$. This indicates that the coating was still adhered to the substrate, but defects such as cracks and bucking could be observed. 
These results can be used to explain the decreasing failure load as a function of temperature observed in figure 7, the higher failure load for plasma nitrided tool steel and the different failure modes observed for the various samples and scratch temperatures. In some conditions, the load support provided by the substrate was able to bear the transferred loads. In the moment the system failed, the harder indenter easily cut through the exposed substrate. This resulted in a system failure that was sudden and with little or no previous deformation, as observed for all samples at room temperature, sample $\mathrm{B}$ at $300^{\circ} \mathrm{C}$ and sample $\mathrm{C}$ in all conditions. On the other hand, soft substrates failed to provide sufficient load bearing capacity, and were plastically deformed at a load lower than the necessary for coating failure. In this case, coating remained adhered on the severely deformed substrate until the indenter is able to break it away and reveal the substrate, as observed for sample A at more than $300^{\circ} \mathrm{C}$ and sample $\mathrm{C}$ at $500^{\circ} \mathrm{C}$.

However, it is likely that substrate softening is not the only factor governing failure load. For instance, samples $\mathrm{A}$ and $\mathrm{B}$ showed considerable plastic deformation at $300^{\circ} \mathrm{C}$ and $500^{\circ} \mathrm{C}$ before the coating broke from the substrate: it is possible that the plasticity of the coating increased at high temperature, as indicated by Fox-Rabinovich [4].

\section{CONCLUSIONS}

A methodology for the mechanical characterization of thin hard coatings on tool steels from room temperature up to $500^{\circ} \mathrm{C}$ and in open atmosphere has been developed. Test results are consistent and show good repeatability. From the obtained results, the following conclusions can be drawn: 
- System performance is clearly affected by temperature: failure load is reduced as temperature increases.

- The load bearing capacity provided by surface nitriding notably increases scratch resistance in all the studied temperature range. The presence of a hard white layer further increases this support.

- Relative performance improvement provided by substrate nitriding is reduced at the highest temperature $\left(500^{\circ} \mathrm{C}\right)$, but is still noticeable.

- Both performance improvement through substrate nitriding and reduction in failure load as temperature increases can be explained through the better load bearing capacity provided by a harder substrate. To a lesser extent, however, coating properties are also affected by temperature and affect overall system performance.

\section{ACKNOWLEDGEMENTS}

Authors wish to thank $\operatorname{Dr}$ Arnd Mueller from Oerlikon Balzers for his support and collaboration.

This work was partially funded by the Catalan government through ACC1Ó under grant TECRD12-1-0012. J Pujante also acknowledges the support received from the Commission for Universities and Research of the Department of Innovation, Universities and Enterprise of the Catalan government under the scholarship 2010TEM24. 


\section{REFERENCES}

[1] S. T. Gonczy, "An ASTM Standard for Quantitative Scratch Testing of Thin, Hard Ceramic Coatings", Int J Appl Ceram Tech (2005) 422-428

[2] P. J. Blau (Ed), "ASM Handbook vol 18: Friction, Lubrication and Wear Technology", ASM International (1992), Materials Park OH, USA

[3] D. N. Allsopp, I. M. Hutchings, "Micro-scale Abrasion and Scratch Response of PVD Coatings at Elevated Temperatures", Wear 251 (2001) 1308-1314

[4] G. S. Fox-Rabinovich, B. D. Beake, J. L. Endrino, S. C. Veldhuis, R. Parkinson, L. S. Shuster, M. S. Migranov, "Effect of Mechanical Properties Measured at Room and Elevated Temperatures on the Wear Resistance of Cutting Tools with TiAlN and AlCrN Coatings", Surf Coat Tech 200 (2006) 5738-3742

[5] G. S. Fox-Rabinovich, J. L. Endrino, B. D. Beake, A. I. Kovalev, S. C. Veldhuis, L. Ning, F. Fotaine and A. Gray, "Impact of annealing on the microstructure, properties, and cutting performance of AlTiN coating", Surf Coat Technol 201 (2006) 3524

[6] Y. He et al. "Effect of prior plasma nitriding applied to a hot work tool steel on the scratch resistant properties of PACVD TiBN and TiCN coatings. Surf Coat Tech 201 (2006), pp 2534-2539

[7] J.C.A. Batista, C. Godoy, V.T.L. Buono, A. Matthews. "Characterisation of duplex and non-duplex (Ti, Al)N and Cr-N PVD coatings", Mat Sci Eng A-Struct 336 (2002), pp 39-51

[8] J.C.A. Batista, C. Godoy, V.T.L. Buono, A. Matthews. "An approach to elucidate the different desponse of PVD coatings in different tribological tests", Surf Coat Tech 174-175 (2003), pp 891-898.

[9] N X Randall, G Favaro, C H Frankel. The effect of intrinsic parameters on the critical load as measured with the scratch test method. Surf Coat Tech 137 (2001) 146-151

[10] H Ichimura, Y Ishii. Effect of Indenter Radius on the Critical Load in Scratch Testing Surf Coat Tech 165 (2003), 1-7 


\section{Tables}

Table 1: Summary of sample characteristics

\begin{tabular}{|c|c|c|c|c|}
\hline Sample & Substrate & White layer & Nitriding depth & Coating \\
\hline A & \multirow{3}{*}{$\begin{array}{l}\text { DIN } 1.2344 \\
\text { 52HRC }\end{array}$} & - & - & \multirow{3}{*}{$\begin{array}{c}\mathrm{AlCrN} \\
3 \pm 0.2 \mu \mathrm{m}\end{array}$} \\
\hline B & & - & $87 \pm 2 \mu \mathrm{m}$ & \\
\hline $\mathrm{C}$ & & $15 \pm 0.1 \mu \mathrm{m}$ & $274 \pm 1 \mu \mathrm{m}$ & \\
\hline
\end{tabular}


Table 2: Test parameters used in high temperature scratch tests

\begin{tabular}{|c|c|}
\hline Sliding velocity & $10 \mathrm{~mm} / \mathrm{min}$ \\
\hline $\mathbf{L}_{\mathbf{0}}$ & $1 \mathrm{~N}$ \\
\hline $\mathbf{d L} / \mathbf{d x}$ & $\begin{array}{c}10 \mathrm{~N} / \mathrm{mm}(\mathrm{Lc}>10 \mathrm{~N}) \\
5 \mathrm{~N} / \mathrm{mm}(\mathrm{Lc}<10 \mathrm{~N})\end{array}$ \\
\hline Temperature & $30^{\circ} \mathrm{C}, 300^{\circ} \mathrm{C}, 500^{\circ} \mathrm{C}$ \\
\hline
\end{tabular}


Table 3: Comparison of results of scratch tests with a Rockwell C indenter and modified scratch test

\begin{tabular}{|c|c|c|}
\hline Sample & $\begin{array}{c}\text { Delamination load Lc2 } \\
\text { (RWC) }\end{array}$ & $\begin{array}{c}\text { Delamination load Lc2 } \\
\text { (modified test) }\end{array}$ \\
\hline A & $55 \pm 1 \mathrm{~N}$ & $8.8 \pm 0.6 \mathrm{~N}$ \\
\hline B & $>100 \mathrm{~N}$ & $13.2 \pm 1 \mathrm{~N}$ \\
\hline C & $>100 \mathrm{~N}$ & $25.3 \pm 2.4 \mathrm{~N}$ \\
\hline
\end{tabular}




\section{List of figure captions}

Figure 1.- Cross-sectional cuts of samples B (a) and C (b). Diffusion layer can be identified as a darker shade in the tool steel substrate. White (composite) layer can also be observed in sample $\mathrm{C}$, as a bright phase just below the coating.

Figure 2.- Detail from the carbide blade used in the modified scratch test: a) CAD isometric view, showing corner radius of $400 \mu \mathrm{m}$; b) Lateral view of the mounted blade, sliding direction is left to right. Lines correspond to milimetres.

Figure 3 .- Characterization of the coated systems: a) Hardness and b) Elastic modulus as a function of indentation depth.

Figure 4.- Room temperature modified scratch test on sample A. a) CoF and AE curves; b) scratch track.

Figure 5.- Results of tests performed at different temperatures on sample C, obtained through Optical Microscopy (OM), analysis of the Coefficient of Friction (COF) and Acoustic Emission signal (AE).

Figure 6.- Selected scratch tracks at failure load for Sample A at a) Room temperature (8.8 N) and b) $500^{\circ} \mathrm{C}(4 \mathrm{~N})$.

Figure 7.- Evolution of delamination load Lc2 as a function of temperature for the three studied systems.

Figure 8.- Selected scratch tracks at failure load. a) Sample A at $30^{\circ} \mathrm{C}(25 \mathrm{~N})$; b) Sample A at $500{ }^{\circ} \mathrm{C}(6 \mathrm{~N})$; c) Sample B at $30^{\circ} \mathrm{C}(13 \mathrm{~N})$; d) Sample B at $300^{\circ} \mathrm{C}(10 \mathrm{~N})$

Figure 9.- Cross-profiles of the scratch track at a longitude corresponding to a load of $5 \mathrm{~N}$ at different temperatures. a) Sample A and b) Sample C 


\section{Figures}
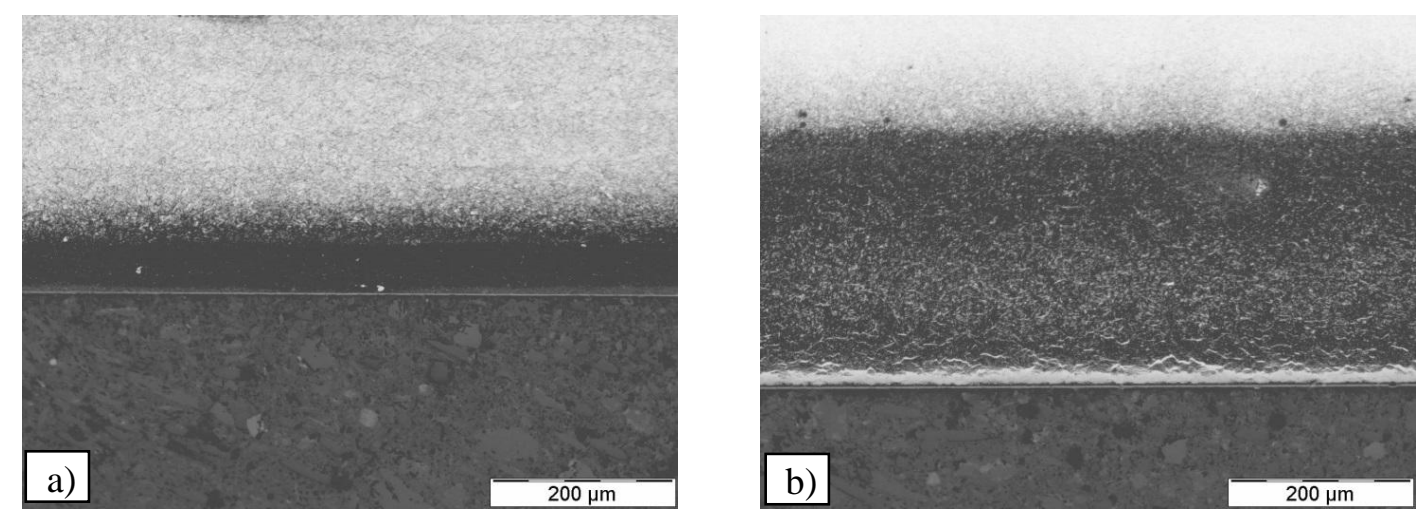

Figure 1 

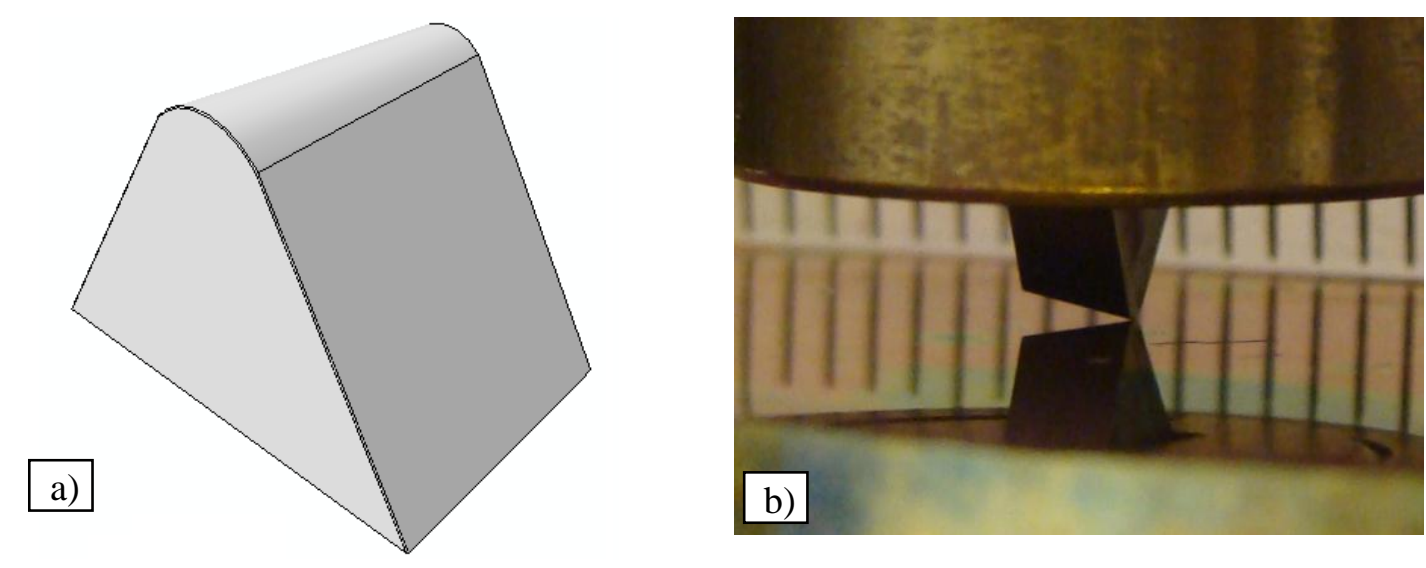

Figure 2 

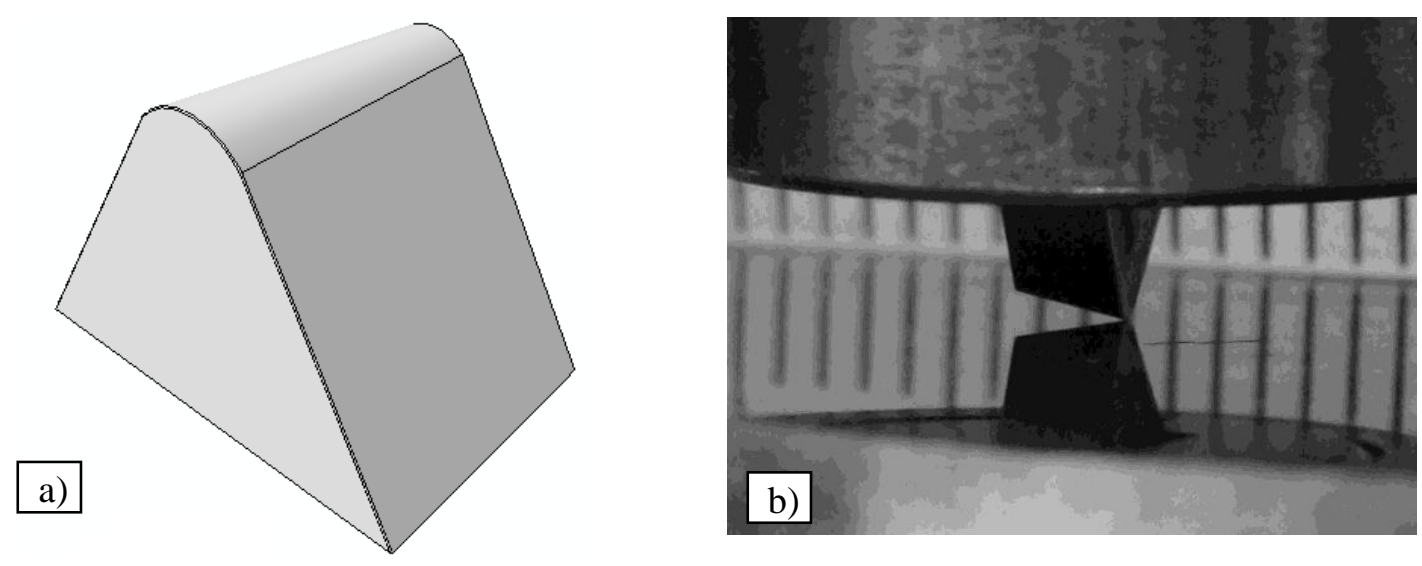

Figure 2 (grayscale version for print) 

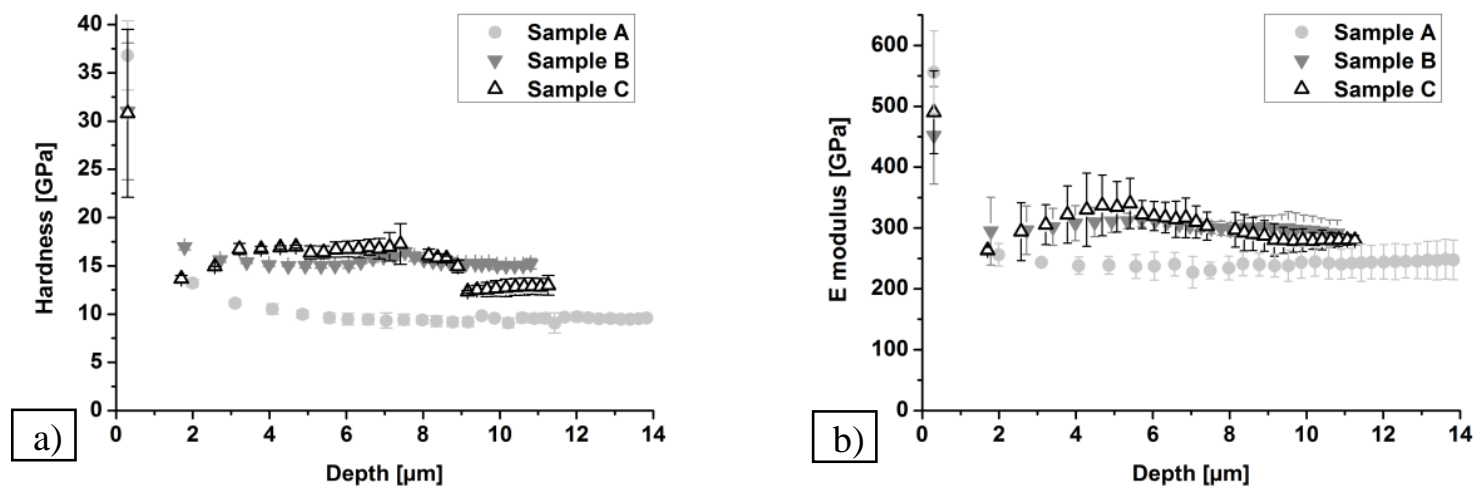

Figure 3 


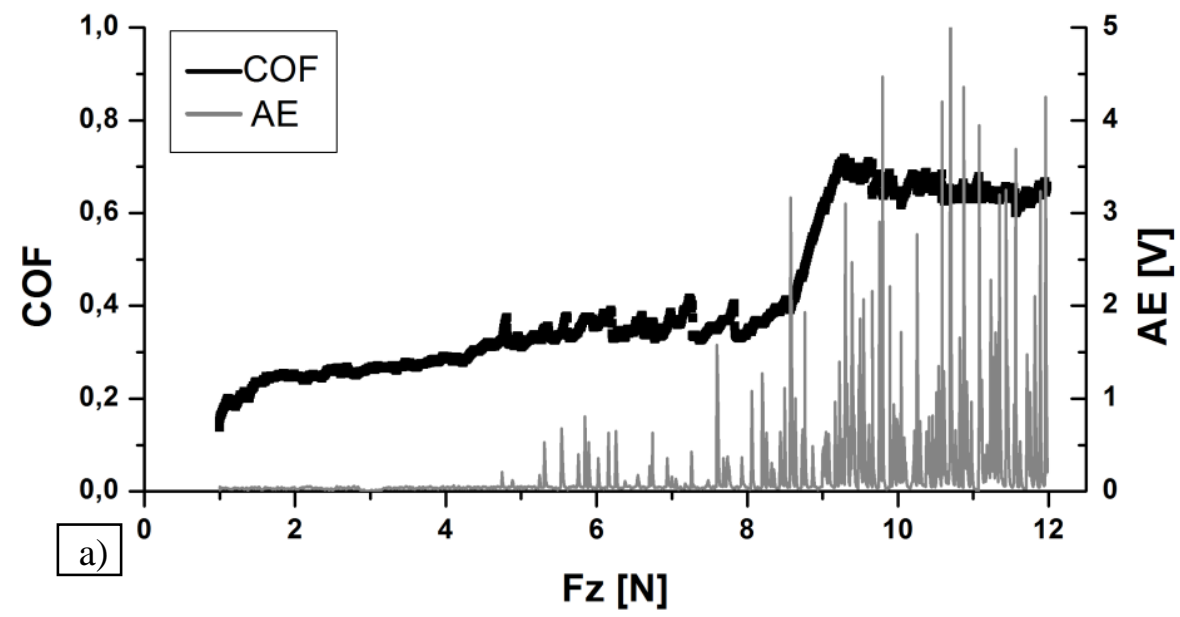

b)

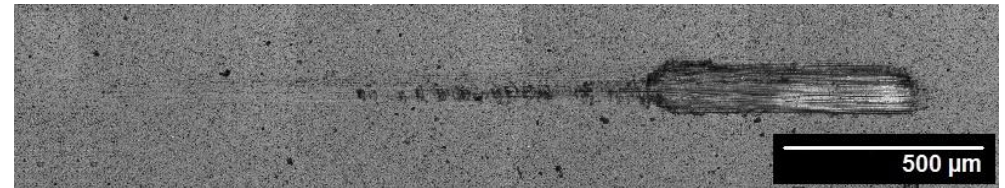

Figure 4 


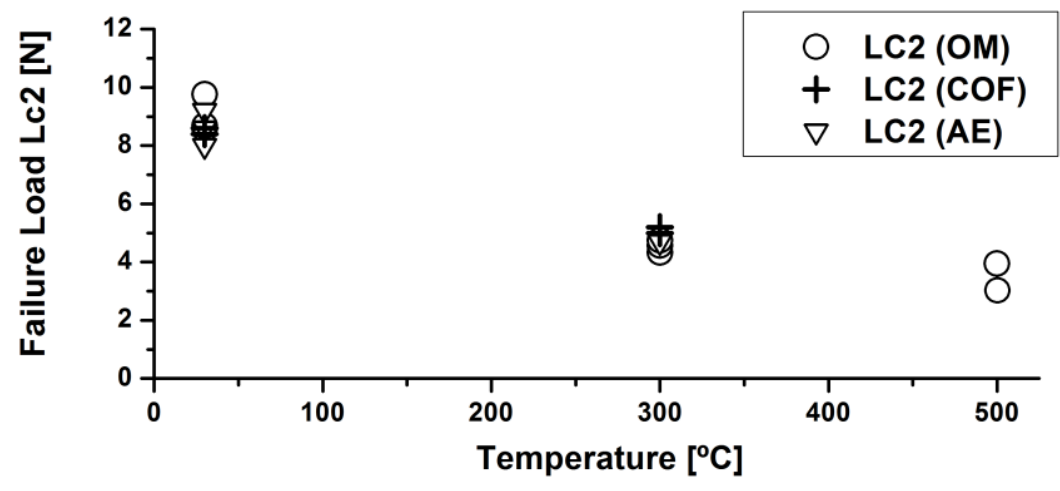

Figure 5 

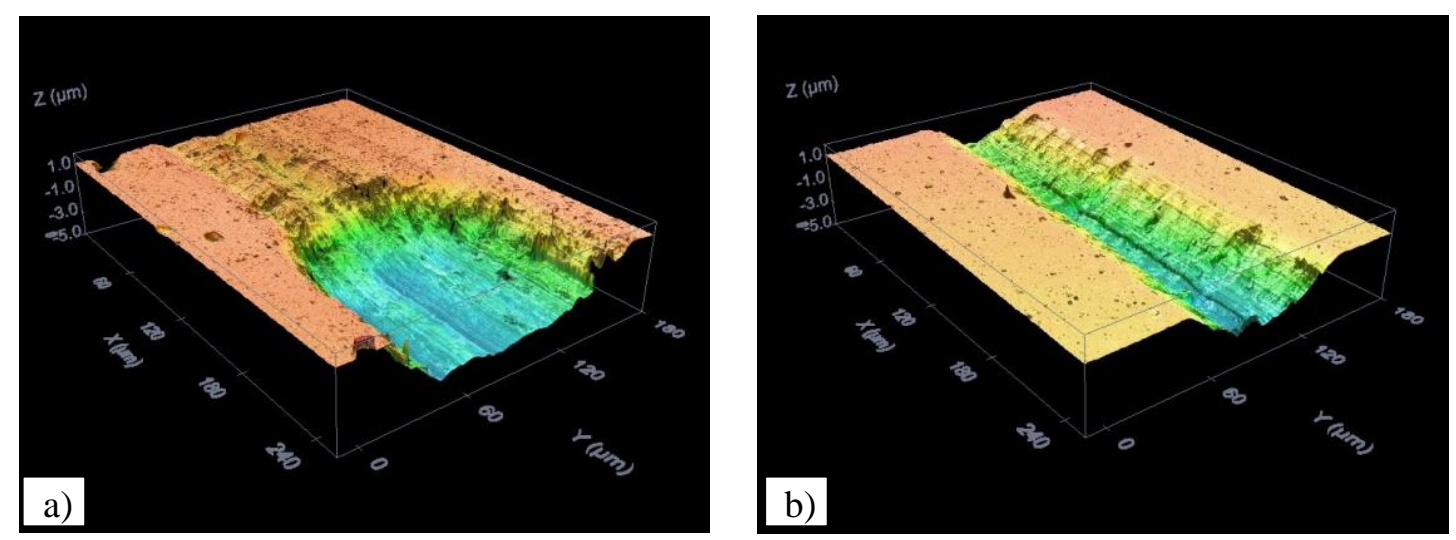

Figure 6 

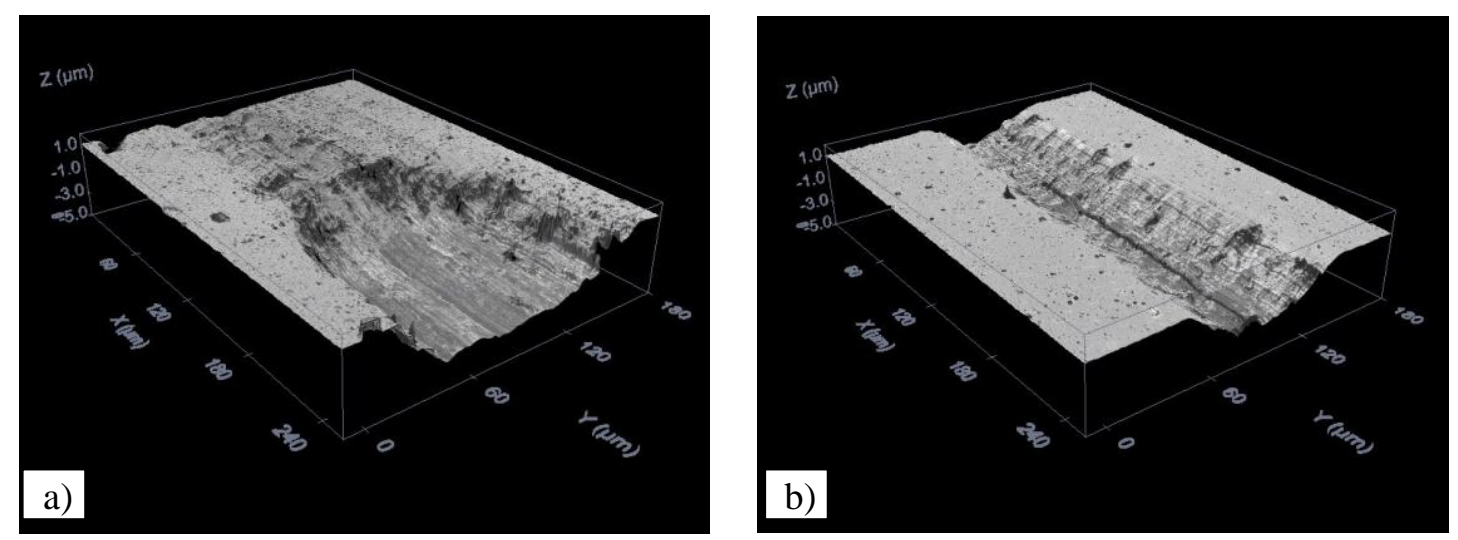

Figure 6 (grayscale version for print) 


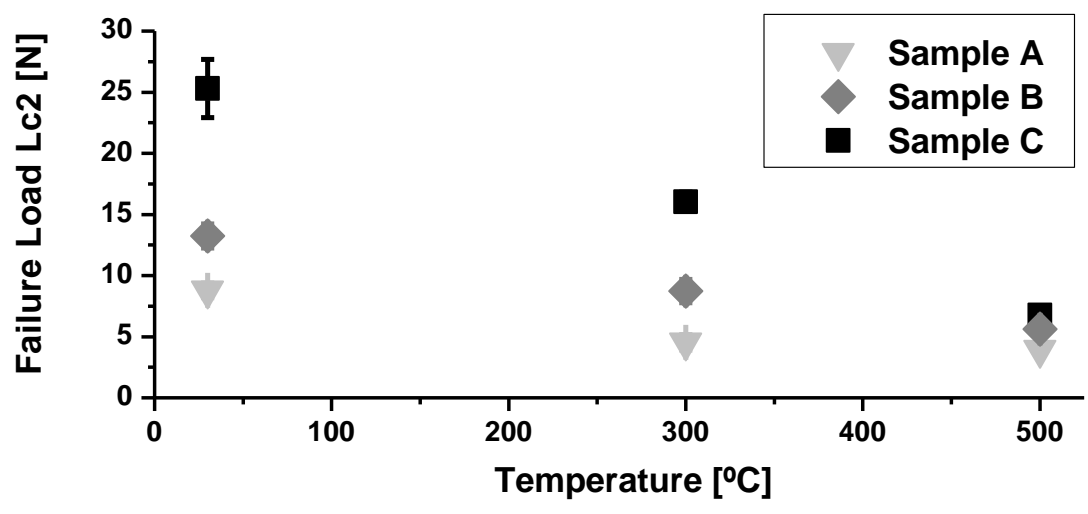

Figure 7 

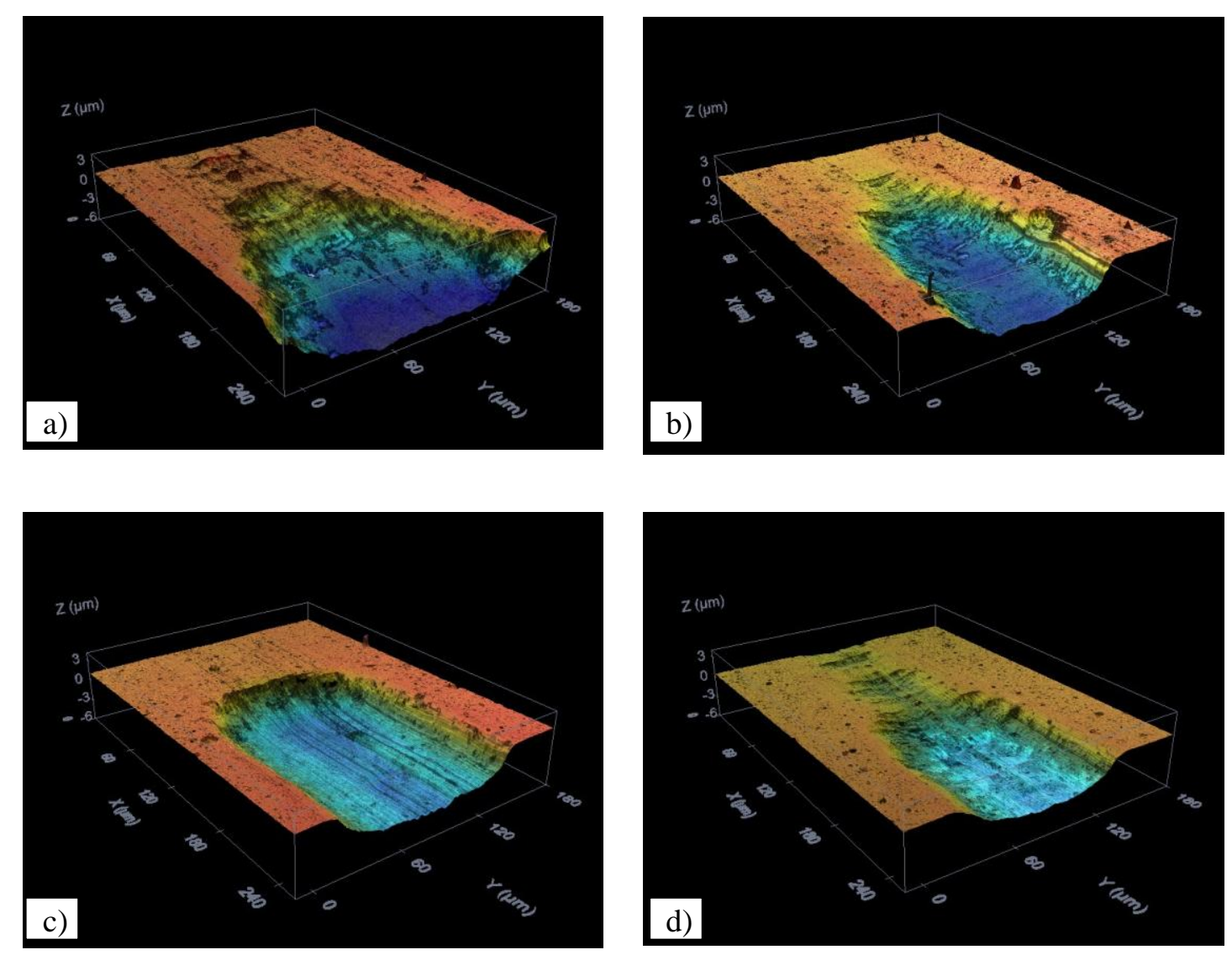

Figure 8 

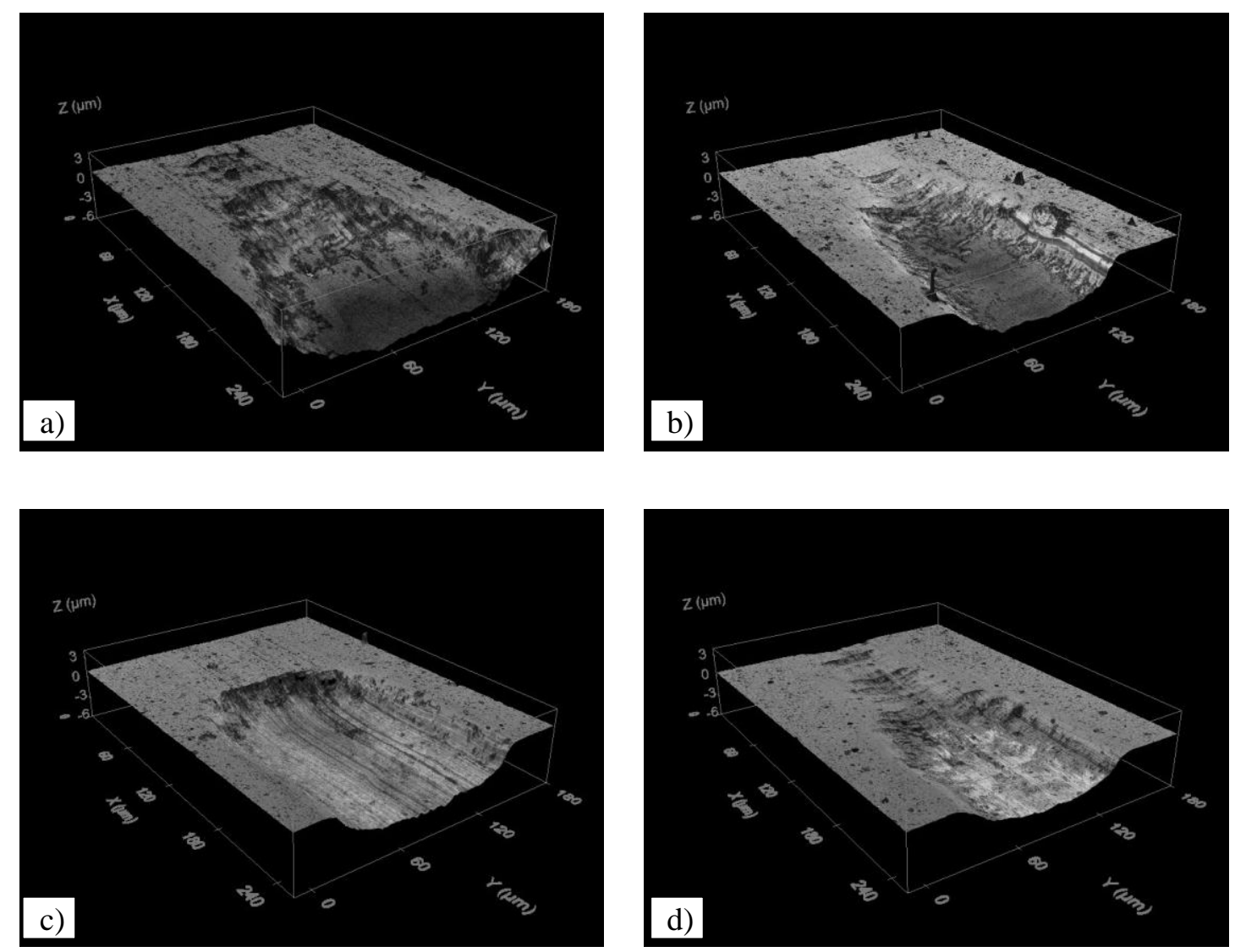

Figure 8 (grayscale version for print) 

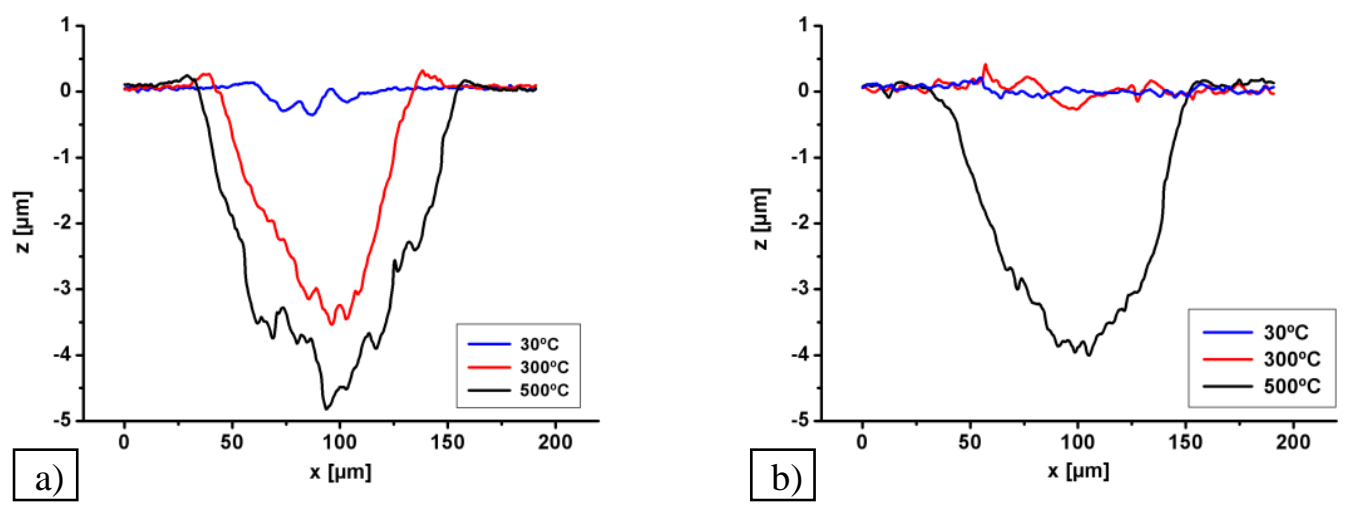

Figure 9 

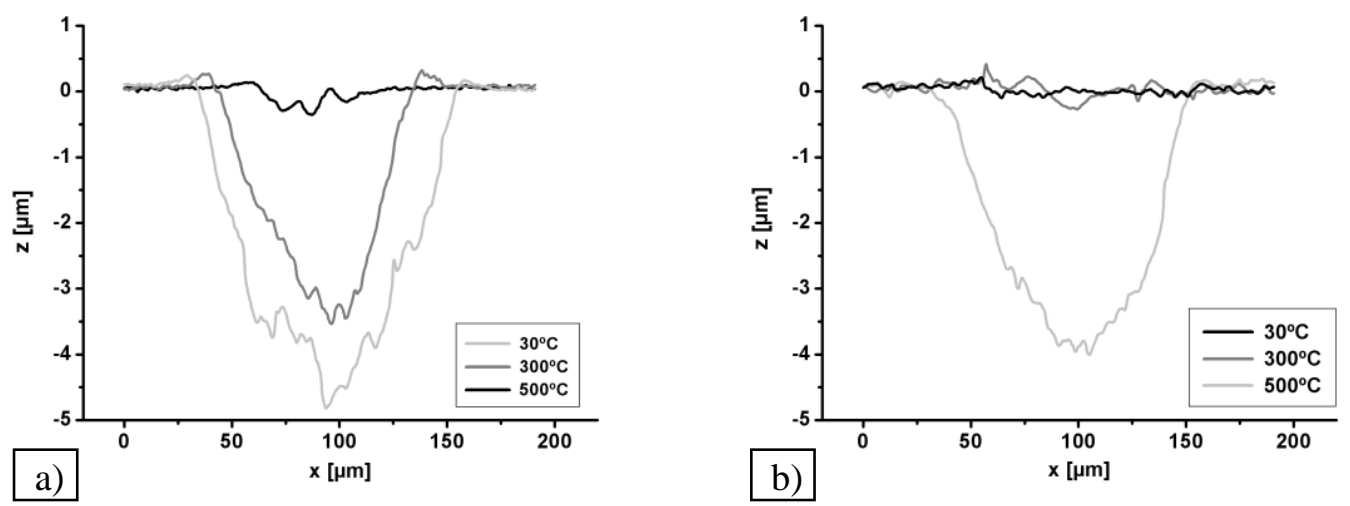

Figure 9 (grayscale version for print) 